\title{
La I Guerra Mundial y el teatro catalán: dos piezas teatrales de Ambrosi Carrion y Avel·lí Artís i Balaguer
}

\author{
World War I and the Catalan Theater: Two Plays of Ambrosi \\ Carrion and Avel-lí Artís i Balaguer
}

\author{
Óscar Fernández Poza \\ (UCM) \\ oskarfp20@ hotmail.com \\ Recibido: abril de 2016. Aceptado: mayo de 2016.
}

Resumen: En el presente artículo se pretende observar el impacto de la I Guerra Mundial en la cultura catalana a través del análisis comparado de dos obras teatrales con dicho conflicto por tema.

Palabras clave: Literatura Catalana Contemporánea, I Guerra Mundial, Literatura, Teatro, Avel-lí Artís i Balaguer, Ambrosi Carrion.

\begin{abstract}
In this article it is to observe the impact of World War I in the Catalan culture through comparison between two plays with the conflict by topic analysis.
\end{abstract}

Paraules clau: Contemporary Catalan Literature, World War I, Teatre, Avel·lí Artís i Balaguer, Ambrosi Carrion.

\section{ESPAÑA Y LA I GUERRA MUNDIAL}

Durante la Gran Guerra, España no jugó un papel directo en la contienda, en buena medida por haber sustentado su neutralidad ante el conflicto ${ }^{1}$. No obstante, como los países beligerantes, sufrió consecuencias políticas, económicas y sociales, dividiéndose la sociedad española en dos bandos (DiazPlaja 1973), aunque, como indica D. Martínez Fiol, «la divisió entre pro-aliats i pro-alemanys no va afectar tota la població espanyola, sinó sobretot classes

${ }^{1}$ El gobierno de Eduardo Dato declaró la neutralidad del país, ante la falta de intereses directos de España en el conflicto y la incapacidad de aportar recursos (Fuentes Codera 2014: 39-43). 
mitjanes, professionals i intel-lectuals» (Martínez Fiol 1988: V). Esta división que, en buena medida, se corresponde con las ideologías políticas, también se reflejará en la sociedad catalana del momento, aunque el posicionamiento de sus diferentes sectores no fue uniforme en función de unos y otros combatientes. Entre las diferentes posiciones defendidas cabía la coincidencia con la decisión estatal, como se puede comprobar en las siguientes palabras de Francesc Cambó:

[...] no'm preocupa gran cosa el que guanyin Alemanya i Austria, o el que la victoria sigui de l'agrupament de potencies que amb elles estan en guerra. Lo que'm preocupa molt fondament, és el paper que li quedarà reservat a Espanya, dintre'l mapa polític d'Europa, en la nova fórmula «d'equilibri europeu» que s'establirà com a conseqüencia del gran trontoll actual [...] El Congrés Internacional que fixarà la situació de tots els Estats d'Europa després d'aquesta guerra, pot ser (jo no dic que ho siga) un moment esplèndit per a que la nostra diplomacia supleixi la falta d'ideal col-lectiu del poble espanyol i prepari un període ascensional per a la vida d'Espanya (Cambó 1914: 1)².

Mientras tanto y como recoge D. Martínez Fiol, desde la posición contraria se veía la oportunidad de plantear ciertas reivindicaciones políticas catalanas, aquellas que pudiera facilitar el triunfo del bando aliado:

la caiguda de totes les monarquies, la conversió d'aquestes en repúbliques i el deslliurament de les nacionalitats oprimides. Per extensió, fins i tot, podia significar que a l'acabament de la guerra l'Estat espanyol esdevingués una República Federal, forma de govern amb la qual es creia que es podria assolir una solució autonomista per a la qüestió o plet nacional català (Martínez Fiol 1988: X).

Una de las cabezas visibles de ese posicionamiento fue Antoni Rovira i Virgili, quien, en una serie de discursos pronunciados en octubre de 1914 en el CADCI de Barcelona (Rovira i Virgili 1915: 148-155, 156-164; Martínez Fiol 1988: 79-85, 86-94), recoge las premisas favorables a ese criterio; o, así mismo, en el «Manifest dels Catalans», redactado por él y donde se realiza una «apuesta para una mayor autonomía catalana en la Europa de posguerra» (Fuentes Codera 2014: 81).

Por su parte la derecha española, contando con representantes catalanes, apoyó el bando germano, siempre dentro de la neutralidad por la que abogaba el estado español (Fuentes Codera 2014: 41). Tal posición queda documentada con la aparición de publicaciones que expresaban su apoyo al Reich (Martínez Fiol 1988: XX) o con el manifiesto «Amistad Hispano-Germana» publicado por Jacinto Benavente en 1915 en La Tribuna, documento también firmado por intelectuales catalanes, donde se expresaba «la más rendida admiración y simpatía por la grandeza del pueblo germánico, cuyos intereses son perfectamente armónicos con

2 Véase también el artículo de Pere Coromines (1914: 1). 
los de España» (Fuentes Codera 2014: 101)3. Desde la documentación de índole literaria escrita en catalán y atendiendo a la que ha tenido más eco dado el peso de su firma, al menos habrá que mencionar las gloses dedicadas por Eugeni D'Ors al conflicto. Se trata de Lletres a Tina (1914-1915), columnas incluidas en su Glosari y de las que derivaría el volumen Tina i la Guerra Gran (1915, reed. 1935) donde revisaba y suprimía algunos contenidos tanto por el devenir de la guerra como por los debates intelectuales establecidos (v. Morgades 1993: c-cii). Destáquese que el pensador novecentista encaró el conflicto como una guerra fratricida entre los pueblos europeos, lo que en la glosa del 8 de agosto de 1914 y como cierre de la misma resolvería con mayúsculas: «LA GUERRA ENTRE FRANÇA I ALEMANYA ÉS UNA GUERRA CIVIL» (D'Ors 1993: 20).

En cuanto a la vida económica, no se dejaron de sufrir el caos y el desconcierto en los primeros meses de la contienda; principalmente en «los círculos comerciales e industriales barceloneses y vascos [...] hicieron zozobrar algunas empresas que dependían del capital extranjero al tiempo que los depositantes se apresuraron para retirar sus fondos de los bancos» (Fuentes Codera 2014: 40). Pero con el transcurso del conflicto, España, gracias a su neutralidad, se benefició económicamente ya que pudo abastecer a los dos bandos. Ante esta estrategia, se ha comprobado que el país experimentó un inicial despegue industrial, principalmente en el sector textil, crecimiento que no obstante fue desigual, resultando beneficiados el País Vasco y Cataluña (Fuentes Codera 2014: 62). Por su parte, el resto del estado sufriría las consecuencias económicas del conflicto europeo, recayendo su peso sobre las clases trabajadoras, lo que provocaría un aumento de las movilizaciones obreras (Fuentes Codera 2014: 115-117).

En esa coyuntura histórica, aquí resumida en extremo, se aprecia cómo Barcelona se convertirá en un centro cultural de primer orden, mediante actuaciones y actividades como la creación de revistas, tertulias, exposiciones, manifiestos a favor de uno u otro bando..., ambiente enriquecido con la llegada de muchos intelectuales europeos que escapaban de la barbarie de la guerra y encontraron en la capital catalana una urbe relativamente cercana y tocada de un creciente cosmopolitismo. Cabe apreciar que estos acontecimientos favorecieron la aparición de una nueva generación de escritores en lengua catalana o influyeron en quienes ya estaban en ciernes, aportándoles nuevos ideales europeizantes, así como criterios a propósito de la modernización del país, aunque estos últimos ya procedieran de principios de siglo (Aulet 1996: 110-112). Tratando sobre la vida musical barcelonesa, R. Alier califica esta época con las siguientes palabras e imagen: «Barcelona fou un oasi de pau on van cercar refugi molts artistes, que van encoratjar la formació de grups d'avantguarda» (Alier 1996: 149). Si, en ese sentido, el musicólogo advierte, por ejemplo, sobre la presencia de los Ballets Rusos de Serge Diaghilev, destaquemos por nuestra parte como hito referencial para la vida literaria la comparecencia en la ciudad de André Breton, presencia notable entre las de otros intelectuales y artistas continentales, de acuerdo con la notificación debida al Dr. J. Molas (1983: 16).

${ }^{3}$ Para conocer mejor los movimientos políticos e intelectuales en Cataluña durante la Gran Guerra, véase J. Casassas (1996: 72-80). 


\section{GUERRA Y LITERATURA}

Las dos obras que analizamos en este artículo - L'altre fill (estreno 1918; ed. 1919) de Ambrosi Carrion (Barcelona 1888-Cornellà de Conflent 1973) y Comèdia de guerra i d'amor (estreno 1921; ed. 1921) de Avel-lí Artís i Balaguer (Vilafranca del Penedès 1881-México 1954)-, dos de los pocos títulos de la dramaturgia catalana que tratan sobre este tema tal y como informan E. Gallén (1987: 432) o D. Coromines (2014: 41), responden a la incidencia que la Gran Guerra tuvo en el medio catalán y a los debates que suscitó en su capital. Solo nos permitimos añadir que, en un artículo publicado en la revista L'Ideal bajo las siglas de E. R. encontramos en su momento una mención a una tercera pieza que trata el asunto de la guerra mundial, noticia que nos ha permitido rescatar aún otro título, Quan passava la tragèdia, obra de Josep Pous i Pagès (1920).

Las dos primeras piezas mencionadas toman el tema de la guerra como eje para sus planteamientos teatrales, pero resolviendo la trama de forma diferente. Ambos títulos no abordan la realidad bélica como un puntual enfrentamiento entre aliadófilos y germanófilos, tal y como se reflejaba en la prensa española y en especial en la catalana (Martínez Fiol 1988), sino que intentan presentar la guerra en escena como tragedia y plantear sus consecuencias, como acabamos de indicar, desde dos puntos de vista diferentes, aunque coincidiendo en los mismos motivos literarios. Avel-lí Artís i Balaguer, en nuestra opinión y coincidiendo en ello con D. Coromines (2014: 53), muestra un discurso pacifista y de corte internacionalista. En esa línea, ya E. R., reseñista del estreno de la obra, comentaba que el discurso del dramaturgo villafranquino, «en lloc de parar-se davant d'un conflicte per analitzar-lo i deduir-ne les consequiències, els abarca tots a la vegada $i$ en forma bella, que nosaltres diríem poemàtica», siendo «la pàgina més sencera que fins ara ha inspirat la nomenada guerra mundial als escriptors de la nostra terra» (E. R. 1921: 176). Por su parte, el discurso de Ambrosi Carrion es diferente, pues se centra más puntualmente en las consecuencias de la guerra y en las heridas tanto físicas como psíquicas que produce.

Según el articulista de L'Ideal que reseñara el mencionado estreno, si algún otro autor catalán había tratado para aquellas fechas el mismo tema y en sentido distinto,

ha sigut tant sols desglosant un cas particular dels molts i variats que de la gran tragèdia hagin pogut sorgir, com ho feu l'Ambrosi Carrion amb el seu drama L'altre fill, i per ridicularisar unes costums arbitràries sugerides en el canvi de posició social d'aquelles pels quals no serví la guerra mes que per a desenrotllar ventatjosament llurs especulacions mercantils, com vegèrem en Quan passava la tragèdia (E. R. 1921: 176).

También F. Curet (1967: 473) advierte sobre las diferencias entre el tratamiento que Avel-lí Artís i Balaguer hace sobre la guerra pues, de acuerdo con su criterio, no es directo ni plantea escenas escabrosas, tal y como sí es el caso de la obra de Ambrosi Carrion. Asimismo, para D. Coromines (2014: 46), la guerra, interpretada según el comediógrafo villafranquino en su comedia, «se'ns ofereix bescanviada en onades de llum i color i traduïda en el llenguatge diàfan 
i guspirejant que li era propi», mientras que en manos del dramaturgo barcelonés «les situacions tètriques hi semblen ficades amb calçador i expressament perquè el lector es dugui les mans al cap».

En cambio y como posible coincidencia por parte de ambos autores, consideramos que las dos obras, como hemos ido reflejando al tratar en particular sobre Comèdia de guerra i d'amor (Fernández Poza 2015: 309), no son obras que se basen en la acción. Añadiríamos también y como posible nexo entre ambas que no llegan a ser piezas de tesis aunque un crítico de La Veu de Catalunya planteará a propósito del estreno de la obra de Avel-lí Artís i Balaguer que la suya sí es una «obra de tesi en la que es posa en pugna les idees de pàtria i d'amor, fent triomfar aquestas» (s.f. 1921: 8). Somos de la opinión de que, como mucho, uno y otro título se acercan a un sencillo análisis de las actitudes de los personajes ante el trauma de vivir una guerra.

\section{DRAMATIZACIÓN DEL CONFLICTO}

Es curiosa la elección tanto en Comèdia de guerra i d'amor como en L'altre fill de un espacio coincidente como lugar de acción por parte de sus dos autores, el de «una masia». En ambas obras se elige como espacio de representación la masía, construcción emblemáticamente catalana y que ya había merecido su literaturización -pensando en producción teatral, recuérdese La creu de la masia (1873) de Frederic Soler, Serafí Pitarra, lo que también poéticamente se habría elaborado mediante composiciones muy divulgadas como La masia dels amors (1866) de Francesc Pelagi Briz i Fernández-, situando ahora y en las dos ocasiones el mencionado indicio de catalanidad en un país innominado y en un tiempo bélico asociado al primer conflicto mundial, de acuerdo con E. Gallén (1987: 432, 437). En la primera de ellas, la escena se ubica en el exterior, dando la acotación sobre los elementos decorativos sobrados detalles acerca del conocido espacio rural:

d'una hisenda d'aspecte senyorial, de parets de pedra patinades pel temps, voltada de vinyes, dintre una vall extensa. [...] En el cantó, i a certa alçària, dintre un nínxol, hi ha una imatge barroca tallada en fusta i policromada. Davant seu penja una llanterna.

La casa té una ampla portalada, amb pedrissos a ambdós costats i sengles obertures. A l'esquerra, i seguint cap al fons, un marge d'uns dos pams d'alçada, que tanca l'era. Passos al mig, esquerra i fons. En últim terme s'estén el panorama de la vall, assoleiada (Artís i Balaguer 1921: s.p.).

Mientras tanto, la segunda obra transcurre en el interior de la masía que, en su caso y a la vez «és hostal a la vora de la carretera» (Carrion 1919: 2), dándose tan solo una descripción simple de su planta baja, adornada con un mobiliario rústico. La diferencia sustancial que encontramos entre las dos piezas acerca de la elección de la masía como espacio de representación es que, en Avel-lí Artís i Balaguer, ese es un espacio cargado de valores positivos, acerca de los cuales cabe pensar en la asociación que en tal sentido reali- 
zaría el espectador catalán; mientras que, para Ambrosi Carrion, se trata de un simple espacio para su argumento aunque, cierto es, con tintes negativos a causa de un hecho delictuoso de alcance argumental sobre el que volveremos posteriormente.

De acuerdo con lo expuesto inicialmente, el tema de ambas obras es la guerra y sus consecuencias, presentando coincidentes motivos literarios; temática a la que también es cierto se incorpora el tema del amor, así mismo tratado de forma diferente según los autores. Comèdia de guerra i d'amor escenifica los acontecimientos que se suceden en «una masia» durante la época de la vendimia, en un país indeterminado y en una época conflictiva dado el enfrentamiento con una nación vecina; en L'altre fill los hechos se prolongan en el tiempo, durante unos cuatro años, duración que es coincidente con la de la guerra.

En las dos piezas, mediante los personajes se expresan los miedos y el odio entre los enemigos, a la vez que se propone cómo el amor puede ser un instrumento idóneo para la salvación de las almas desgraciadas, aquellas que sufren los horrores de la guerra y el sufrimiento que provoca. Pero el amor tiene una finalidad diferente para cada autor. Para Avel-lí Artís i Balaguer, como ocurre a lo largo de su producción teatral (Fernández Poza 2015: 154), el amor es empleado como medio con el que resolver el conflicto fundamental de cada pieza, creando en este caso redes de relaciones amorosas entre los enemigos; para Ambrosi Carrion es el amor del esposo el medio que se utiliza como sentimiento suficiente con el que perdonar a la protagonista de la afrenta que ha sufrido, la muerte de la hija y el nacimiento de un hijo fruto de la violación sufrida (Carrion 1919: 47-48).

De este modo, las pequeñas miserias y alegrías de la vida cotidiana hacen aflorar diversos asuntos literarios en las obras. Son los que van desde el concepto de patria hasta el del odio al enemigo y el horror ante el conflicto bélico. Ambos autores suben a escena algunos asuntos que resultan coincidentes. Uno es el mencionado concepto de patria, visto en gran medida bajo una misma perspectiva, aquella en la que el individuo se muestra por encima de la comunidad; así se puede comprobar mediante las palabras de uno de los prisioneros de guerra de la obra de Avel-lí Artís i Balaguer, quien proclama su libertad y afirma que su «vida ja no pertany a la pàtria. Per ella l'he exposat cent vegades... la sort ha volgut que pogués contar-ho..., doncs ara és ben meva... I ningú no pot discutir-me-la» (Artís i Balaguer 1921: 49). El mismo autor, en otro de los pasajes de su obra y merced a la intervención de otro de sus personajes, realiza un alegato a favor de la paz y del amor, sentimiento que no tiene fronteras y que siempre valdrá como medio para resolver la guerra y lograr la reconciliación entre los enemigos:

Igal: Que em diguin, en aquest moment, que d'obtenir jo la vostra amistat en pot venir la desfeta dels exèrcits del meu país, i jo em quedo amb l'amistat vostra.

Càrsia: Molt galant!... I per una dona entregaríeu la pàtria! 
Igal: La pàtria!... La pàtria no és l'ambició d'un rei, que això, en tot cas, fóra el que jo abandonaria... La pàtria és un tros de terra, només; el tros de terra just on naixem, vivim i morim... Com més gran volem fer-la, menys pàtria la sentim.

Càrsia: Potser teniu raó. Jo estimo molt els de casa, fins els del poble, però que són de lluny, ja no m'interessen gens.

Igal: La pàtria són uns braços que ens lliguen: els dels pares, els de l'amor, el dels fills... Mentre ens hi trobem bé, tot pot semblar-nos la pàtria. Aquest recó d'una era, tant plàcid en aquesta hora, tenint-vos a vós al costat, no és tant plaent com el millor racó de la pàtria? Vós i jo ens diem enemics, i cada u sent dintre seu com va acostant-se a l'altre... Quantes dones hi haurà, filles de la meva terra, que no sabrien escoltar-me amb el fervor que vós ho feu! Quants homes hi haurà, compatricis vostres, que us hauran dit paraules i no us hauran interessat com les meves!... Si és tan vell com el món l'averany de que l'amor aterrarà les fronteres (Artís i Balaguer 1921: 94-95).

En el caso de Ambrosi Carrion, el concepto de patria se encuentra más desarrollado, pudiéndose observar dos modos de comprenderlo. Uno es el personificado por Gabriel y Úrsula en el primer acto de la obra, cuando ponen el acento en el individualismo, planteando que la patria está en uno mismo y en las personas que les rodean, concepto en buena medida cercano al del comediógrafo villafranquino; y el otro es representado por el Avi, padre de Gabriel, quien lo enarbola como un valor colectivo. En la lucha entre esos dos criterios triunfará el segundo, valorándose positivamente el sacrificio del individuo en beneficio de la comunidad.

El primero de esos modos, como ya se ha mencionado, lo expresa Gabriel hablando de la libertad de decisión de los hombres que no tienen por qué estar sujetos a la ley (Carrion 1919: 8-9); en esta línea, Úrsula se expresa en los siguientes términos: «Ni govern ni això que en diuen Pàtria, poden disposar de la vida del meu Andreuot... Les mares no hem parit als fills perquè els portin a matar...» (Carrion 1919: 9). A través del alegato contra la guerra y la defensa de los trabajadores y del pueblo, Ambrosi Carrion nos presenta su concepto de patria, mediante las siguientes palabras de Gabriel:

[...] el poble, la gent que treballa, els humils, en una paraula, que no tenen altre patrimoni que els seus braços com jo mateix, abominen i maleeixen aquesta guerra a que els llença el desig ambiciós, d'uns quants...

$[\ldots]$

La bojeria, l'ambició d'uns quants s'encomana, i tot i maleint, hi han homes, massa per dissort, que es senten arrocegats. I van a morir cantant, com aquells que deia la mare Ursula, borratxos de vi o de gloria, que és igual. Van a morir cantant, per lo que no donará ni un boci de pa als seus fills, ni una hora d'alegria. Que la victoria és sols pels poderosos, i el venciment per els humils que ho paguen, fins amb la vida, mentre que als altres no els costa una hora de no dormir. El mal i la desgràcia tenen ales, i amb tot això no arriben mai als qui són enlaire 
[...]

Per la Pàtria, per això que em diuen Pàtria, i que no sabem mai on és, sinó per lo que deman de nosaltres... hem de córrer a matar o morir, o, lo que és pitjor, restar tarats per tota la vida. I desprès que? haurem defensat la Pàtria, mes ella no sabrà donar-nos en pac altra cosa que set pams de terra, o fer-nos inútils per l'amor, pel treball, que és la única, la veritable pàtria (Carrion 1919: 12).

Como contrapartida, la visión contrapuesta del concepto de patria, representada como se ha dicho por el Avi, defiende que el bien colectivo debe marcar el destino, que es el de la patria, lo que implica el buen o mal hacer de los gobernantes. Ambos modos de afrontar todo ese asunto se evidencian en el siguiente diálogo entre padre e hijo:

L'Avi: (Engrescant-se) Entremig dels crits i les descàrregues, al toc furiós de les trompetes, quan els homes es llencen com un allau de ferre i foc, guiats per les banderes desplegades, llavors sents lo que és la Pàtria; i és tan gran el goig que et dóna, que la vida et sembla poc per poguer sentir-lo.

Gabriel: Doncs jo aquest goig no el conec ni el vull conèixer. Jo lluitaria quan em prenguessin les collites de les meves terres, quan vegés menaçada la meva casa, els meus: llavores sí. Mes, altrament, no hi tinc cap dret a la vida dels altres.

$[\ldots]$

L'Avi: Ens van prendre un troç de la terra nostra. Cal que ens la tornin. Ara ha arribat l'hora. Portem una taca que ens cal rentar-la.

Gabriel: Una taca mig de sang i per rentar-la voleu més sang? Es tot lo que pot constar-nos, i això no vol dir res, veritat? S'encén la guerra per l'ambició dels de l'altra banda o per l'odi dels d'aquí, i perquè dels uns volen un troç de terra que no és seu, perquè els altres determinen no dona'ls-hi, corre la sang, i els homes, empesos, no per la seva voluntat, sinó per la dels menys, que són els qui manen, corren els uns contra els altres a esquinçar-se la carn, a deixar les terres ermes $i$ els pobles en runes. I als qui pateixen $i$ la feconden amb la seva suor, als qui viuen d'ella i per ella, ningú els pregunta, ningú els demana si volen anar-hi i se'ls empeny com a remats al escorxador. I una volta s'ha acabat, els qui guanyen engeguen les campanes, canten i esvaloten... la terra aquella, passa de les mans dels uns a les dels altres... I els dissortats que han lluitat per defensar-la, vencedors o vençuts, es troben a la fin amb la terra erma, la llar en runes, el cos inútil per a el treball, esguerrats per sempre de cos i d'ànima. I això encara quan no ho paguen amb la vida. Mentre que els qui van desencadenar la guerra es queden tranquils i satisfets, perquè no tenen temor de Déu ni consciencia de la sang vessada, ja que an ells no els hi ha costat una sola gota (Carrion 1919: 15-16).

En cuanto al tema primordial en que coinciden los dos autores y que a su vez engloba sus obras, el de la guerra y los motivos literarios que se desprenden de él, Avel-lí Artís i Balaguer y Ambrosi Carrion formulan una clara crítica 
contra lo que significa la guerra y los desastres que provoca. Véase cómo en Comèdia de guerra i d'amor es considerada como perniciosa porque el «seu record és una desesperança que no poden suportat els meus sentits... I en un dia com avui, amb tanta serenor al cel i tanta alegria a la terra -en aquestes mojades de terra que ens volten- em sento tan sola, que més valdria morir» (Artís i Balaguer 1921: 14-15). Para los dos dramaturgos la guerra es negativa, no solo por los resultados económicos (Carrion 1919: 32) sino también por los desajustes sociales y las desgracias familiares que se derivan (Carrion 1919: 3), tal y como se puede comprobar en el siguiente diálogo de L'altre fill:

Andreuot: (Entrant a la cuina) La guerra, maleitsiga, la guerra (Una pausa)

Joanic: (Que és al fons props la porta.) Es ben estrany que sigui tant poruc. Un sicotás com ell...

Beneta: Calla! Si vingués això de la guerra que dius, seria per tots una gran desgràcia.

El Carreter: Es veritat.

Beneta: Encara que tot això dèu ésser cosa dels governs.

El Carreter: Coses del govern que els pobres ho paguem amb la pell.

Joanic: Però té massa por.

Beneta: Ja t'he dit que callis. Au a la cuina a veure si et necessiten. (Al carreter) Ell pateix per la seva mare. No té ningú més al món. I ha sofert tant per pujar-lo!... Si el cridessin es quedaria sola... i pobre dona, no val ja per res.

El Carreter: Tot és prou trist. Si em cridessin a mi, amb tantes boques com deixo al darrera!...

Beneta: Déu no voldrà enviar-nos una desgràcia tan gran...

El Carrater: No se'n cuida d'aquestos coses.

Joanic: Doncs a mi m'agradaria anar a la guerra (Sortint a fora)

Beneta: Ni per riure ho diguis (Carrion 1919: 4).

En consonancia con ello y para Avel-lí Artís i Balaguer, la guerra incide en todos los seres humanos:

I els seus a la nostra terra es trobem talment.. Això, això, és el que dóna intensitat a la tragèdia. L'horror del combat no fóra ta agut si no portés aquests seguicis. En el combat jo he vist que tots érem diferents de com som ara. Tu, Caleb, tan honrat, tan bon cor, amb l'arma a les mans érets sanguinari... Tu, Henan, érets espaventable amb la teva gosadia.. Tu, Tubal, ànima senzilla, en un moment he vist alçar-te per damunt dels herois... I és que en la lluita no ens donem comte de la nostra naturalesa d'homes. Ens sentim que som coses que pertanyen a la pàtria, com les fulles dels arbres, com les herbes dels prats, com els raïms de les vinyes... Però, passada la febre, en sentir-nos novament 
homes, ens donem compte de les malvestats comeses i donaríem la vida per poder néixer de nou i ésser deslliurats de culpa (Artís i Balaguer 1921: 50).

Otro de los asuntos literarios en que coinciden los dos dramaturgos es el del tratamiento del odio contra el contrario o el desconocido, sentimiento primario que está presente desde las primeras escenas de ambas obras. Ese odio está expresado a través de la figura de un anciano -en Comèdia de guerra $i$ d'amor es un pastor y en L'altre fill es el padre del protagonista-, figura que representa lo tradicional y lo ancestral. Los dos ancianos cuentan por qué se ha llegado a esa situación; el anciano pastor de la primera de las obras informando a unos niños y con tono solemne, tanto sobre el motivo de las guerras como acerca de lo inevitable de su continuidad:

No, no s'haurà acabat, rosseta. La nostra guerra no acabarà mai mentre Nostre Senyor no acabi amb aquesta raça de bergantells que tenen enveja de la nostra terra. I per a atuir-los, vosaltres fareu la guerra com la vàrem fer nosaltres, com la fan els vostres pares, perquè al món no ni cabem ells i nosaltres (Artís i Balaguer 1921: 12).

En la obra de Ambrosi Carrion, por su parte, el Avi desea la revancha: «(Entrant amb el pare Marcel, amb un diari a la mà, molt content.) Vaja! Això ja és un fet. Ja ens ha arribat l'hora. Ara sí que la prendrem la revenja!» (Carrion 1919: 13); lo que se puede escuchar en las siguientes palabras: «[...] Nosaltres no la desitjàvem ara aquesta guerra mes ja que ells ho volen, llamp de Déu! que sia. Els hi donar-ens una lliçada que mai més hi tornaran... Vos ho juro! [...] Si com jo hi haguessis estat a l'altra guerra, i t'haguessin ferit per dugues vegades...» (Carrion 1919: 14).

Ante tal criterio enarbolado por ese protagonista de Ambrosi Carrion, existen personajes en la obra de Avel-lí Artís i Balaguer que intentan luchar contra este sentimiento de odio. Es el caso de Marta, la «mestressa» de la finca, quien critica que se cuenten supuestas historias de heroísmo a los niños, sembrando el odio entre ellos: «Ja estic cansada de sentir-vos els sermons! El mal no és a mi, és a la terra a qui el feu, servant aquest caliu d'odi... Bé és pitjor això, per a nosaltres, que els canons de l'enemic!» (Artís i Balaguer 1921: 13). Marta intentará combatirlo, predicando el amor al resto de los habitantes de la masía (Artís i Balaguer 1921: 34-35), animando al conocimiento del enemigo mediante el amor y llegando a contar con la ayuda de los soldados enemigos.

Otro asunto literario presente es el del horror ante el conflicto bélico, el que va desde el miedo y la reacción a las explosiones de artefactos, también ante las heridas sufridas tanto físicas como psicológicas por los combatientes, hasta la compasión por el desplazamiento de los refugiados (Carrion 1919: 18). Respecto al pavor por las mencionadas explosiones, encontramos una diferencia entre los dos autores. En el caso de Avel-lí Artís i Balaguer este asunto se encuentra más desarrollado que en el de Ambrosi Carrion, pero los dos coinciden en presentar la destrucción que producen las bombas. En L'altre fill se muestran los efectos de la explosión en la acotación inicial del segundo acto, «dalt de la paret i en el sostre un gran esboranc obert per l'esclat d'un obús» (Carrion 1919: 19); 
mientras que en Comèdia de guerra i d'amor se saca a escena a la población que, aún lejos de los combates, halla a las puertas de sus casas la consternación que provoca la lejana explosión de una granada, tal y como puede comprobarse en la siguiente acotación:

Magda: La darrera desgràcia que veiem ens sembre sempre la més grossa.

(Una detonació formidable, de granada esclatada a prop [...] van d'ací, d'allà, arrecerant-se les unes amb les altres. L'esverament les ha eтmиdides. Sara, com folla, salta, brinca de l'un pedrís a l'altre. És un remolí que no troba moment d'aturar-se. Laban, com sí un sentiment de vergonya l'impel-lís a desafiar la mort, s'acosta al fons; Marta, que ha sortit de la casa, en veure-li l'acció, el crida, amb un esgarip sortit de l'anima:)

Marta: Laban!...

(Aquest crit, com un ressort, asserena a les dones. Totes s'agrupen a l'esquerra, com si temessin una repercussió de la detonació. Isca, en veu molt baixa, formula la pregunta, que ningú li respon.)

Isca: Són aquí?

(Pel fons apareix Samuel, seguit de Lamec. El pastor ve gairebé arrossegant-se, abraçat a un anyell amb el cap sagnant. Lamec es queda al fons amb Laban) (Artís i Balaguer 1921: 38).

La guerra provoca la destrucción y la pérdida de los seres queridos. Ambos autores muestran en escena ese desastre máximo a través de los diálogos de sus personajes (Artís i Balaguer 1921: 19-20, 25; Carrion 1919: 7, 8). También y en ese sentido, Ambrosi Carrion no deja de mencionar los destrozos que realiza el ejército enemigo tras su retirada:

L'Avi: Sí, Perquè haveu fet tant de mala a la terra i a les vides nostres, que lo millor que podeu fer és acabar amb tots nosaltres. Ja que vos en teniu d'anar, ja que vos treuen, no deixeu res darrera vostre cremeu, destruiu, acabeu amb les poques vides que resten. I emporteu-vos-en també les terres, i, entremig d'elles, els cadávres que heu fet, perquè quan sigueu a la vostra pàtria emmetzinin l'aire amb la seva fetor i acabeu tots inflats de la vostra mateixa podridura. I feu una muntanya de tots els que han mort a vostres mans, de tot quan haveu trocejat, de tot lo que haveu robat, i al cim, claveu-hi aquesta criatura que du la sang vostra, com a gallartet d'ignomínia (Carrion 1919: 32).

Pero el escritor barcelonés va más allá que el villafranquino en sus planteamientos en cuanto a este asunto, ya que la obra termina argumentalmente con el fin de la guerra. Esto le permite incluso presentar las consecuencias que ha traído la paz: la falta de trabajo y el listado de muertos que serán llorados por sus familiares (Carrion 1919: 37, 38).

Los dos autores coinciden ante el motivo de las heridas de la guerra, presentando no solo las consecuencias físicas sino también las psicológicas. Así puede 
verse en la obra del comediógrafo villafranquino, en el caso de Lamec, quien ha perdido un brazo (Artís i Balaguer 1921: 16), habiéndole sido implantado uno de hierro, «ara que saben reemplaçar el braç de carn per un ferro... que no serveix per a dur un cistell de raïms» (Artís i Balaguer 1921: 17). Por su parte, en la obra del dramaturgo barcelonés, Joanic sufre una herida de bala por fuego amigo (Carrion 1919: 35-36), mostrando sus miedos (Carrion 1919: 37), esto último frente al Avi que, a pesar de sufrir heridas, aún conserva ánimos para ir a la guerra: «Mes jo tot i tenint aquest braç (L'esquer) inútil, m'en sento orgullós perquè al mirar-me'l recordo que vàreig servir a la nostra pàtria. I si ara, llamp de Déu! em volguesin prendre, encara hi aniria per dexar-hi aquest altre, o lo que calgués» (Carrion 1919: 14).

Para concluir con el análisis aludiremos a dos nuevas diferencias entre ambas obras: el tema del amor y el asunto del tratamiento del enemigo. En el caso de Avel-lí Artís i Balaguer y acorde con el mensaje que pretende dar con su obra, la presencia del enemigo se aborda con benevolencia, intentado igualarlo con los habitantes de la masía y presentándolo como un igual ante sus captores (Artís i Balaguer 1921: 53); todo ello con una actitud alegre a la vez que resignada en el caso de los prisioneros, lo que no evita que estos últimos se quejen de su situación, principalmente por las condiciones en que viven (Artís i Balaguer 1921: 52), al tiempo que no dejan de sufrir los horrores de la guerra como se puede comprobar en la siguiente intervención de uno de los cautivos:

No cal pas que us horroritzeu. Potser era el vostre pare aquell que va atravessar al meu germà, caigut sota els meus peus, que van xipollejar en la seva sang calenta!

[...] Un es torna masell. Al principi, passava dies, setmanes, mesos, vivint en plena horror... Però quan van començar a caure anys, un darrera l'altre, i ens vèiem sempre igual els que teníem la sort de veure'ns, ens anàvem acostumant tant a tot allò, que una hora de treva era matar-nos... Els primers dies de tenir-me al camp de concentració, vaig estar mallat... No m'hi sabia avenir el silenci de l'espai!... La naturalesa a la qual jo m'havia acostumat era tant distinta d'aquella que contemplava! Allí hi mancava el brunzir de les bales, l'esclat dels canons, el cràter dels obusos enfonsant-se a la terra... (Artís i Balaguer 1921: 93).

Mientras tanto, en el texto de Ambrosi Carrion los enemigos tienen un papel diferente ya que, como presencia invasora, son un elemento represor pues están ocupando una tierra que no les pertenece y son causantes de los robos y de los destrozos en las casas, en especial en la masía (Carrion 1919: 23-25); y también son dañinos en lo psíquico, como muestra el caso de la dueña de aquella, quien ha sido víctima de una violación. No obstante, como ocurría en Comèdia de guerra i d'amor, uno de los soldados enemigos critica la guerra:

Jo vivia tranquil em la meva ciutat, treballant i content. Tinc una filla que estava casada amb un bon noi, del mateix ofici meu. També era rellotger. La guerra se'l va dur i el van matar. Conta com vàrem quedar-nos. Jo era llavors l'únic puntal de la casa; amb mi vivien la noia i la meva nèta: una criatura que 
és rossa com el blat i més blanca que la llet. La feina havia minvat per la guerra, quasi no n'hi havia; mes amb penes i treballs anàvem vivint, perquè la lluita havia dut a la ciutat una misèria espantosa. I això, que allavors, guanyàvem. Conta com estaran ara, que m'escriuen demanant si el puc enviar menjar, perquè allà tothom s'està morint de misèria; quan m'escriuen demanant-me roba, perquè es moren de fret; sabates, perquè la meva nèta va descalsa i... Ni vull pensar-ho! (Carrion 1919: 23-24).

Por último, nos centraremos en el tema del amor que, como queda advertido, es tratado de diferente forma por uno y otro autor. En Avel-lí Artís i Balaguer es empleado como medio para resolver los problemas de convivencia que se producen entre los habitantes de la masía y los prisioneros y, de este modo, conseguir la verdadera paz. Los prisioneros no dejan de sentir el odio de algunas de las mujeres (Artís i Balaguer 1921: 70), pero la actitud de Marta consigue revertir ese sentimiento y hace que el amor triunfe sobre el odio. A favor de ese triunfo final de la razón y la buena convivencia están las palabras de Igal, verdadero alegato de alcance pacifista:

I qui no té un dolor de què doldre's! Allà, a les línies de foc, quan l'home deixa d'ésser home per convertir-se en un objecte, tots els planys, totes les queixes, tots es dolors, tots els vituperis, totes les amargors, s'aferrassen dintre l'ànima i creiem que totes plegades hem de venjar-les en el primer desventurat que lluita enfront... Però aquí, en la quietud santa de la terra lliurada de la desfeta, que junts venim a treballar-la perquè l'any vinent torni a florir, per què no hem de pactar una treva que acabi aquestes rancúnies que no ens deixarien en repòs un moment de la vida? Per què nosaltres, pobres insignificàncies, hem d'imitar els nostres reis i els nostres governants? Ells, que decreten les guerres perquè no hi van, no donen cap valor a la vida dels seus súbdits, i per això les sacrifiquen sense comptar-les; però nosaltres, que no tenim altra riquesa que la vida, enlloc d'amargar-nos-la per a venjar agravis dels altres, procurem fer-la plaent, que no és pas de tanta durada! (Artís i Balaguer 1921: 74).

El comediógrafo villafranquino presenta en escena la alegría del triunfo del amor a través de la fiesta y de los bailes (Artís i Balaguer 1921: 96-97) y su obra concluye con ello; más aun, acaba con el grito final de «Visca l'amor» (Artís i Balaguer 1921: 110). Frente a esa estrategia, Ambrosi Carrion no emplea el amor como medio para resolver el conflicto dramático sino que lo añade como un problema, llegando incluso, tal vez, a imponerse como el tema primordial de la obra, reduciendo el peso de la guerra. En L'altre fill aparecen tanto el amor de pareja como el materno-filial, como es obvio relacionados entre ellos.

El amor de pareja se romperá, no solo a causa de la guerra, sino también porque Eugènia ha dado a luz un nuevo hijo, fruto de la violación de un soldado enemigo (Carrion 1919: 29). Un nuevo hijo que, cierto es, viene a sustituir a la hija del matrimonio, muerta a causa de una explosión, complicación argumental que probablemente está en el origen de la depresión de la protagonista (Carrion 1919: 20, 21). En todo caso, el nuevo nacimiento cobra relevancia dentro del 
argumento, ya que provoca reflexiones sobre el rechazo que produce en la sociedad y aún más en aquellas circunstancias. El autor plantea diferentes posturas, desde el asesinato del fruto de la violación (Carrion 1919: 21, 29-30, 33) a la compasión y la comprensión del sufrimiento de la madre (Carrion 1919: 19, 21). La obra concluirá con el reencuentro y, a la postre, la ruptura definitiva de la pareja de protagonistas. Ambrosi Carrion lanza el mencionado mensaje de comprensión y de perdón por parte de Gabriel, pero no evita su huida final hacia adelante, plasmada con el definitivo abandono de su esposa (Carrion 1919:47-48). Trabajando argumentalmente con elementos de tal alcance es como Ambrosi Carrion llega a dramatizar incluso las derivaciones postreras de la guerra; opción ante la que Avel-lí Artís i Balaguer prefiere entonar un canto de redención que parece definitivo y universal.

Para acabar, dada la atención que la literatura suscitada en su primer centenario por la I Guerra Mundial está animando -encuadre dentro del cual hemos rescatado los títulos tratados con anterioridad- y en la medida en que esa producción nos acerca a la sensibilidad y al posicionamiento del espectro social español, sería interesante calibrar la recepción de las obras revisadas. En esa dirección, no hemos podido ir más allá de la reseña mencionada sobre la pieza de Avel-lí Artís i Balaguer, allí donde se remite a las de Ambrosi Carrion y Josep Pous i Pagès.

\section{BIBLIOGRAFÍA}

\section{Corpus}

Artís i Balguer, A. (1921) Comèdia de guerra i d'amor: tres actes, Barcelona, impresa a Casa de l'autor.

Briz i Fernández, F. P. (1866) La masia dels amors: poema popular, Barcelona, Librería de Juan Roca y Bros.

Carrion, A. (1919) L'altre fill: drama en tres actes, Barcelona.

D’Ors, E. (1993) Lletres a Tina. Obra catalana d'Eugeni d'Ors. VII, Barcelona, Quaderns Crema.

Pous i Pagès, J. (1920) Quan passava la tragedia: farsa en quatre actes, Barcelona, Salvador Bonavia, Llibreter.

Soler, F. (1873) La creu de la masia, Barcelona, Llibreria d'Eudalt Puig.

\section{Estudios}

Alier, R. (1996) «La música del Noucentisme», en Història de la cultura catala. El Noucentisme (1906-1918). Volumen VII, Barcelona, Edicions 62, pp. 139-158. 
Aulet, J. (1996) «Les bases inicials de la democratització de la societat catalana», en Història de la cultura catala. El Noucentisme (1906-1918). Volumen VII, Barcelona, Edicions 62, pp. 105-138.

Cambó, F. (1914): «Espanya davant la Guerra Europea. Al fer-se la pau», La Veu de Catalunya, 25 de agosto de 1914, p. 1.

Casassas, J. (1996) «Les bases inicials de la democratització de la societat catalana», en Història de la cultura catala. El Noucentisme (1906-1918). Volumen VII, Barcelona, Edicions 62, pp. 37-80.

Coromines, D. (2014): Avel-lí Artís i Balaguer i Barcelona: vida i obra, Barcelona, Ajuntament de Barcelona.

Coromines, P. (1914) «Per l'amor de França», El Poble Català del 13 de septiembre de 1914, p. 1.

Curet, F. (1967) Història del Teatre Català, Barcelona, Aedos, pp. 525-530.

Díaz-Plaja, F. (1973): Francófilos y germanófilos, Dopesa, Barcelona.

E. R. (1921) «Teatre Espanyol: Comèdia de guerra i d'amor», L'Ideal, núm. 9-10, pp. 176-177.

Fernández Poza, O. (2015) Avel-lí Artís i Balaguer (1881-1954), comediógrafo e impresor-editor. Entre la plenitud del cambio de siglo y el exilio, Madrid, Universidad Complutense de Madrid.

Fuentes Codera, M. (2014) España en la Primera Guerra Mundial. Una movilización cultural, Tres Cantos-Madrid, Akal.

Gallén, E. (1987) «El Teatre», Història de la literatura catalana, J. Molas (dir.), Barcelona, Ariel, vol. 9, pp. 413-462.

Martínez Fiol, D. (1988) El catalanisme i la Gran Guerra (1914-18). Antologia, Barcelona, La Magrana.

Molas, J. (1983) La literatura catalana d'avantguarda. 1916-1938. Selecció, edició i estudi, Barcelona, Antoni Bosch.

Morgades, J. (1993) «Estudi introductori» a Lletres a Tina. Obra catalana d'Eugeni d'Ors. VII, Barcelona, Quaderns Crema, pp. ix-cxii.

S. F (1921): «Estrena de «Comèdia de guerra i d'amor»», La Veu de Catalunya (23-IV-1921), p. 8.

Rovira i Virgili, A. (1915): «Necessitat de que tot nacionalisme tingui una política internacional», Revista Anyal, pp. 148-155.

Rovira i Virgili, A. (1915): «Posició de Catalunya davant del problema europeu», Revista Anyal, pp. 156-164.

Rovira i Virgili, A. (1915): «Manifest dels Catalans», L'Esquella de la Torratxa, 26 de marzo de 1915, p. 194. 
